\title{
Strong bonds and small home range in a resident bottlenose dolphin community in a Marine Protected Area (Brittany, France, North-East Atlantic)
}

Marie Louis ${ }^{1,2}$, Mickael Buanic ${ }^{3}$, Cécile Lefeuvre ${ }^{3}$, Phillipe Le Nilliot ${ }^{3}$, Vincent Ridoux ${ }^{1,4}$, Jérôme Spitz ${ }^{1}$

1. Observatoire Pelagis, UMS 3462 CNRS-Université de La Rochelle, 17000 La Rochelle, France

2. Scottish Oceans Institute, University of St Andrews, East Sands, St Andrews, Fife, KY16 8LB, UK

3. Parc naturel marin d'Iroise, Pointe des Renards, 29217 Le Conquet, France

4. Centre d'Etudes Biologiques de Chizé, CNRS-UMR 7372, 17000 La Rochelle, France

Keywords: Social structure, ranging patterns, photo-identification

Social associations among individuals can reveal behavioral strategies that maximize an individual's fitness (van Schaik 1989, Silk et al. 2003, Frere et al. 2010a, Kappeler et al. 2013). Possible advantages of social bonds include decreased predation risks, cooperation to catch and defend resources, transfer of information, care for another, or increased calf survival. Disadvantages include competition for resources or mates, facilitated transmission of pathogens, and increased aggression or infanticide rates (see detailed review in Krause and Ruxton 2002). The trade-off between the costs and benefits incurred is influenced by predation risks, the availability of resources including habitat, prey, and access to mates, and density dependent factors (Alexander 1974, Rubenstein and Wrangham 1986). Hence, ecological variability such as the availability of suitable habitat or food resources may shape social variability in terrestrial and marine mammals (Karczmarski et al. 2005, Wittemyer et al. 2005). For instance, ecological factors may have a strong influence on the social structure of bottlenose dolphins, Tursiops spp. (Connor et al. 2000). These species form fission-fusion communities (i.e., we consider a community as an entity formed of individuals of the same species that co-occur in space and time and have an opportunity to interact), where associations among individuals are fluid and highly dynamic (Connor et al. 2000). The strength of dyadic associations can be measured using the half-weight index (HWI), which corresponds to the number of times a pair of individuals was observed in the same group over the number of times the individuals were observed in different groups. It ranges from 0 (individuals were never associated) to 1 (they were always associated). In most bottlenose dolphin communities, the mean $\mathrm{HWI}$ is low, around 0.1 indicating a low frequency of associations among individuals (Connor et al. 2000, Wiszniewski et al. 2009, Bouveroux and Mallefet 2010, Daura-Jorge et al. 2012, Louis et al. 2015). However, in some communities, a small number of individuals form strong and longterm associations (such as alliances between males) that are thought to be shaped by ecological factors, kin selection, or mating strategies, or a combination of those (Kreutzen 
et al. 2003; Frere et al. 2010b; Wiszniewski et al. 2010, 2012; Connor et al. 2011). Additionally, the Doubtful Sound (New Zealand) and the Sado estuary (Portugal) dolphin communities have a stable fission-fusion social structure with strong bonds recorded between most individuals (Lusseau et al. 2003, Augusto et al. 2011). Such social structure is uncommon for these species and may be shaped by resource availability (Lusseau et al. 2003, Augusto et al. 2011). Studying the social structure of additional bottlenose dolphin communities may help to better understand its drivers in this species.

Our study focused on a small bottlenose dolphin community, which was first recorded around Sein Island, Brittany, France in the 1980s and monitored until 2001 for population size and habitat use. The community was small ( 20 individuals in

2001) and used a mean area of $6 \mathrm{~km}^{2}$ as determined by focal follow data (Liret et al. 2006). No movements were recorded between the Sein Island community and the closest bottlenose dolphin community of the Molene Archipelago, which is situated around $40 \mathrm{~km}$ north of Sein Island (Liret et al. 2006). Following the creation of a marine protected area (MPA), Parc naturel marin d'Iroise (PNMI), an ongoing photoidentification monitoring effort was implemented from 2014 onward for estimating demographic parameters and habitat use. The objective of this study was to update census size, investigate social structure, and estimate the home range of this community using photo-identification data. Photo-identification data were collected around Sein Island (Fig. 1) from August 2014 to October 2015 during 28 sampling days with good weather conditions (Beaufort sea state $\leq$ 3 ). The island is located $8 \mathrm{~km}$ from the coast of France (Brittany region). The area is characterized by shallow waters (depth ranges from $<1-30 \mathrm{~m}$ ), strong tidal currents and a variety of benthic habitats including numerous rocks covered by algae, gravel and maerl bottoms, or sandy sediments. Recordings from the boat during the surveys using MaxSea Marine Navigation Software indicated current speeds of 3-4 kn and up to $5.2 \mathrm{kn}$ during an equinox high tide. Given the strong currents and numerous submerged rocks it was impossible to design line-transect surveys. However, efforts were made to survey the area consistently across the surveys. A typical survey route included a loop around the island and driving around all the rocks on the western part where the route extended $8 \mathrm{~km}$ west of the island. Surveys were conducted at a speed of 5-10 kn from an $8 \mathrm{~m}$ rigid inflatable boat with two or three observers aboard, including one photographer. For the purposes of this work a group of dolphins was defined as all individuals moving in the same direction and engaged in a similar behavioral activity, that were within a $100 \mathrm{~m}$ radius from each other (Wells et al. 1987). When a group of dolphins was sighted, photographs of the dorsal fins and upper backs of encountered individuals were taken by the same observer using a Nikon D300S with a 120-400 mm lens. Photo-identification work usually ended when the photographer decided that he had photos of all the individuals, or more rarely when dolphins showed boat avoidance behaviors. Efforts were made to photo-identify all individuals in the group, which was relatively straightforward given the small size of the community. Photo-identification data treatment was performed by the same observer and followed standardized protocols (Hammond et al. 1990). Individuals were identified from good and very good quality photographs (i.e., in focus, fin entirely visible, angle at ca. 90 or 270). Photos of all individuals were arranged in a catalog, keeping the best and most recent photo for each individual. The best photo for each individual per survey was selected and was matched to the identity catalog of all individuals. All individuals could be recognized using their natural marks (i.e., notches and scars) on both sides of their dorsal fins, therefore, no individual was excluded from the analyses based on its level of markings. Group sizes were inconsistently recorded in the field and were therefore estimated as the number of identified individuals in the photographs for each encountered group. 
Social structure analyses were run using the SOCPROG 2.4 program (Whitehead 2009) implemented in Matlab version 7.6.0. (Mathworks Inc., Natick, MA). A day was considered as the sampling period to avoid demographic effects. We restricted the analysis to adults sighted on more than 10 sampling periods (i.e., survey days) to avoid bias linked to sample size and rarely encountered individuals. Calves (i.e., individuals whose age was estimated to be $<2$ yr due to known birth year according to their first sighting, presence of fetal folds or lines, size and close and repetitive contact with the mother) were excluded as their social affiliations are linked to their mothers. Opportunistic photo-identification data collected in 2013 were used to help determine the year of birth of the calves. Individuals were considered as associates if they were observed in the same group during a sampling period.
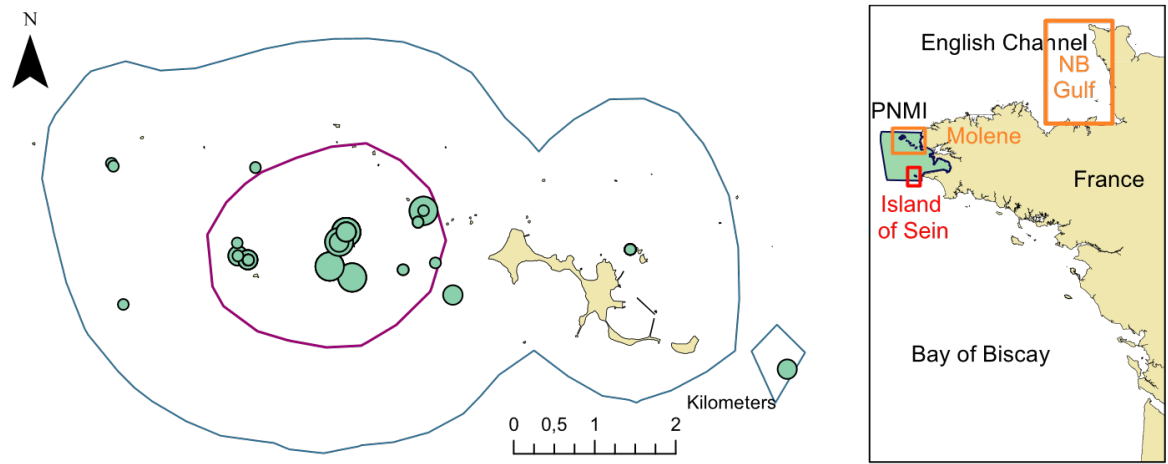

Group size

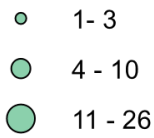

Home ranges

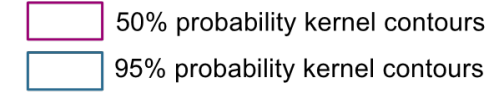

Figure 1. Map of the study area showing the home range (95\% fixed kernel density) and the core area (50\% fixed kernel density) of the dolphin community and the locations of the groups sighted in 2014-2015 classified in three group size classes. The area corresponding to the PNMI (Parc naturel marin d'Iroise) is indicated. The areas where resident bottlenose dolphin communities are observed are indicated in the general map, i.e., "Molene" for the Molene archipelago community and "NB Gulf" for the Normano-Breton Gulf community.

The HWI was used to quantify the strength of associations between pairs of individual dolphins. This index minimizes bias when all the associates are not identified (Cairns and Schwager 1987). Although efforts were made to photograph all individuals present in the group, using the $\mathrm{HWI}$ accounted for eventually missed individuals and is therefore conservative. Additionally, this index is commonly used in bottlenose dolphin social structure analyses, allowing comparisons among studies (e.g., Lusseau et al. 2003, Augusto et al. 2011, Daura-Jorge et al. 2012, Louis et al. 2015). The coefficient of variation of the $\mathrm{HWI}$ (S, the social differentiation) and the correlation coefficient of the true and estimated association matrices $(r)$ were estimated using maximum likelihood procedures. A social differentiation of less than 0.3 indicates a homogenous society, and values of more than 0.5 indicate a well differentiated society. Coefficient $r$ indicates the power of the analysis to represent the true social structure, with 0 indicating an inaccurate representation and 1 an excellent representation. Standard errors (SE) were calculated for $r$ and $S$ from bootstraps with 1,000 replications. A Monte Carlo permutation test was conducted to 
determine whether observed association indices were higher than expected by chance (Bejder et al. 1998; Whitehead 1999, 2008). The matrix of observed association indices was permutated within sampling periods until $P$ stabilized at 10,000 permutations with 1,000 flips. A higher standard deviation (SD) of the observed association indices in comparison with the SD of permutated data indices indicates that preferred and/or avoided associations are present in the community (Whitehead 1999, 2008). The social structure of the community was then examined using a hierarchical cluster analysis with the average linkage algorithm on the association data. A cluster with a cophenetic correlation coefficient (CCC) higher than 0.8 indicates a good representation of social structure (Whitehead 2008). We tested whether there was any subdivision in the community using modularity coefficient, Q, (Newman 2004, Whitehead 2008). Modularity was defined as the difference between the proportion of the total association measured within clusters vs. the expected proportion if pairwise association indices were randomly distributed. A modularity coefficient $\geq 0.3$ indicates significant division among clusters (Newman 2004). We also displayed the social structure as a sociogram showing association indices between individuals that are $\geq 0.5$.

Home range was estimated for the entire community using the fixed kernel-density method (Worton 1989) in R 3.2.3 (R Core Team 2015) using the adehabitatHR package (Calenge 2006). The data were the same as those used for social structure analyses (i.e., we only kept the first sighting if a group was sighted more than once during a day and excluded groups for which no photos were taken to avoid duplicates). The resolution of the smoothing parameter (i.e., the bandwidth value) was estimated using the ad hoc method. The home range was defined using a $95 \%$ contour line and the core area using a $50 \%$ contour line.

Field work was carried out all year round (4 surveys in the winter, 5 in spring, 15 in summer, and 4 in autumn; Fig. 2). Eighty groups were sighted during 28 sampling days (dolphins were sighted during each survey). Thirteen groups were excluded as they were resightings of the same group observed earlier in the day. Seven groups were discarded because no photos were taken or the conditions (i.e., individuals showed boat avoidance behavior or currents were particularly strong) made it too difficult to get good quality photographs, and four groups were excluded because they did not include individuals sighted in more than $10 \mathrm{~d}$. Thus, 56 groups sighted during 25 sampling days were included in the analysis. During a survey day, one main large group was typically observed, with a mean number of 16.4 identified individuals $(S D=5.2$ ) as well as smaller subgroups of one or a few individuals $(x=2.7$, SD $=1.9)$.

Thirty-three dolphins were identified over the study period (2014-2015) including 24 adults or subadults (referred as adults thereafter) and 9 calves. The discovery curve indicated that all adults were rapidly identified after the first surveys (Fig. 2). Census size was 29 individuals, including 24 adults and 5 calves in 2014 (mark-recapture analyses resulted in exactly the same estimation, Louis and Ridoux 2015), and 31 individuals including 24 adults and 7 calves in 2015. All 24 adults sighted in 2014 were resighted in 2015 , suggesting interannual site fidelity. Two adults out of 24 were excluded from the social structure analyses as they did not meet the more than 10 sampling day threshold (they were only observed on 3 and $8 \mathrm{~d}$, respectively). For the 22 remaining individuals, the mean number of sampling days where an individual was recorded was 17.1 (SD = 3.1).

The estimated social differentiation $(S)$ was 0.47 (SE = 0.06), indicating a moderately to well-differentiated society. The correlation coefficient $(r)$ of the true and estimated association matrices was $0.87(\mathrm{SE}=0.03)$, indicating a good power to represent the social 
structure. The mean HWI was $0.50(\mathrm{SD}=0.27)$. This SD was higher than that obtained for the permuted data set $(S D=0.25, P<0.001)$, indicating that the individuals did not associate at random and that there were long-term preferred or avoided associates in the community. The cluster cophenetic correlation coefficient (CCC) was 0.96 , which indicates an effective social structure representation (Fig. 3a). Most individuals were sighted together $50 \%$ of the time (Fig. $3 \mathrm{~b}$ ). In addition, both the cluster diagram and the sociogram indicate one core social entity composed by the majority of the individuals, a smaller entity of three individuals and more solitary individuals (Fig. 3a, b). However, there was no significant division in the community, the maximum modularity $(\mathrm{Q})$ was 0.08 . Including the individual sighted on only eight sampling days in the analyses did not change any of the results significantly (results not shown).

The home range of the community was $33.5 \mathrm{~km}^{2}$ (95\% kernel) and the core area was 5.6 $\mathrm{km}^{2}$ (50\% kernel, Fig. 1). It should also be noted that extensive field work for other environmental or species monitoring was carried out by the MPA fieldwork team in other areas around the island, further offshore from the island, and along the coast of Brittany; and the bottlenose dolphins were never sighted there ( $\mathrm{MB}$, personal observation). The photo-identification catalog of this community was compared with the catalogs of the communities of the Molene archipelago (PNMI catalog, Brittany, France, Atlantic Ocean) and of the Normano-Breton Gulf (Groupe d'Etude des Cetaces du Cotentin catalog, Brittany and Normandy, France, English Channel). No matches were found.

The mean association index of 0.5 in this community is one of the highest ever recorded in published studies on bottlenose dolphins (mean HWI were 0.45 and 0.47 in the Sado estuary and Doubtful Sound communities, respectively; Lusseau et al. 2003, Augusto et al. 2011) while the core home range is one of the smallest. Although no significant community division has been detected, both field observations and social structure analyses indicated one main social group composed of the majority of the individuals that were tightly associated $(\mathrm{HWI} \geq 0.5)$ and individuals that were more solitary or observed in smaller groups. The co-occurrence of these contrasting grouping patterns may reflect contrasting balances between the costs and benefits of living in groups for different individuals (Kappeler et al. 2013). The small groups usually did not include calves. It would be interesting to determine the sex of the individuals as well as the behavioral state of each group to better understand the forces driving these different grouping patterns. Individuals also appeared to show strong site fidelity, and this observation should be confirmed with data collected in additional years. A large amount of time has elapsed between the current data and the dedicated surveys of the mid-1990s; it was thus not possible to reliably compare the two catalogs to further investigate site fidelity. The current data set spanned over 15 mo, which was not enough to fit models of temporal stability of association patterns.

Several factors may drive the relatively atypical social structure observed here for the species. First, demographic factors may play role (Lehmann and Boesch 2004). As the size of this dolphin community is small, individuals may have more opportunities to associate with all the other individuals. However, even if the community size is small, it is possible to observe low average coefficients of associations if the typical group size is small. As an example, the mean HWI among 35 bottlenose dolphins in an estuary in Brazil was 0.05 (Daura-Jorge et al. 2012). Therefore, demographic factors alone cannot explain the strong associations observed among individuals. Ecological factors, in particular resource availability (food and/or habitat), may be important drivers of social structure variation both among and within social mammal communities (Karczmarski et al. 2005, Henzi et al. 2009, Beck et al. 2012, Foster et al. 2012). Here, the small core area used by the community 
and the site fidelity of the individuals suggested that prey may be abundant, which possibly limited trophic competition among individuals. Benefits of living in a group may therefore outweigh the cost, promoting strong social bonds between individuals and the use of a small core area as suggested for the Sado estuary bottlenose dolphin community (Augusto et al. 2011). In addition, winter conditions can be harsh as this open habitat is regularly exposed to strong storms and currents. Calves were not included in the social structure analyses, but were generally observed in the large main group. Two of the three calves born in 2013 disappeared during winter 2014-2015 (unpublished data). Although data were limited during winter, strong bonds among individuals may promote care and protection of the calves. Calf survival is positively influenced by strong and stable bonds between adult females in primates and bottlenose dolphin societies (Silk et al. 2009, Frere et al. 2010a). Predation is unlikely to influence association patterns as no shark bites were ever recorded; this is in contrast to populations exposed to shark attacks (Heithaus 2001). Kin selection (Hamilton 1964) may also play a role in shaping the strong social bonds observed in this community. Between 1994 and 2001, the size of the community increased from 14 to 21 individuals, and this increase corresponded solely to new calves that stayed in the community (Liret et al. 2006), which is likely to have created opportunities for associating with kin. As mentioned above, we could not compare the current data with the mid-1990s to further investigate this hypothesis. To sum up, the social structure of this community might be shaped by a combination of a small group size, low trophic competition, and environmental conditions. This hypothesis could be further investigated by collecting environmental and behavioral data.

Finally, this study provided an updated status on the census size of the Sein Island bottlenose dolphin community that has doubled in size since first census size count using photo-identification data in the same area from 14 individuals in 1992 (Liret 2001) to 31 individuals in 2015. The community seemed, according to photo-identification data, isolated from the other resident bottlenose dolphin communities in Brittany and Normandy. However, information on genetic connectivity was not available. The small home and core range of the community make it particularly vulnerable to anthropogenic pressures, and thus increases the need to protect this habitat. This area is designated as a Special Area of Conservation (SAC) as part of the Natura 2000 Network (European Union Habitats Directive, 92/43/EEC) and a Marine Natural Park under the French regulation. Long-term demographic monitoring is needed to carefully assess the health of this community, which is identified as one of the 16 bottlenose dolphin management units to be assessed in the European Union (ICES 2014) for the Marine Strategy Framework Directive (MSFD, 2008/56/EC). 


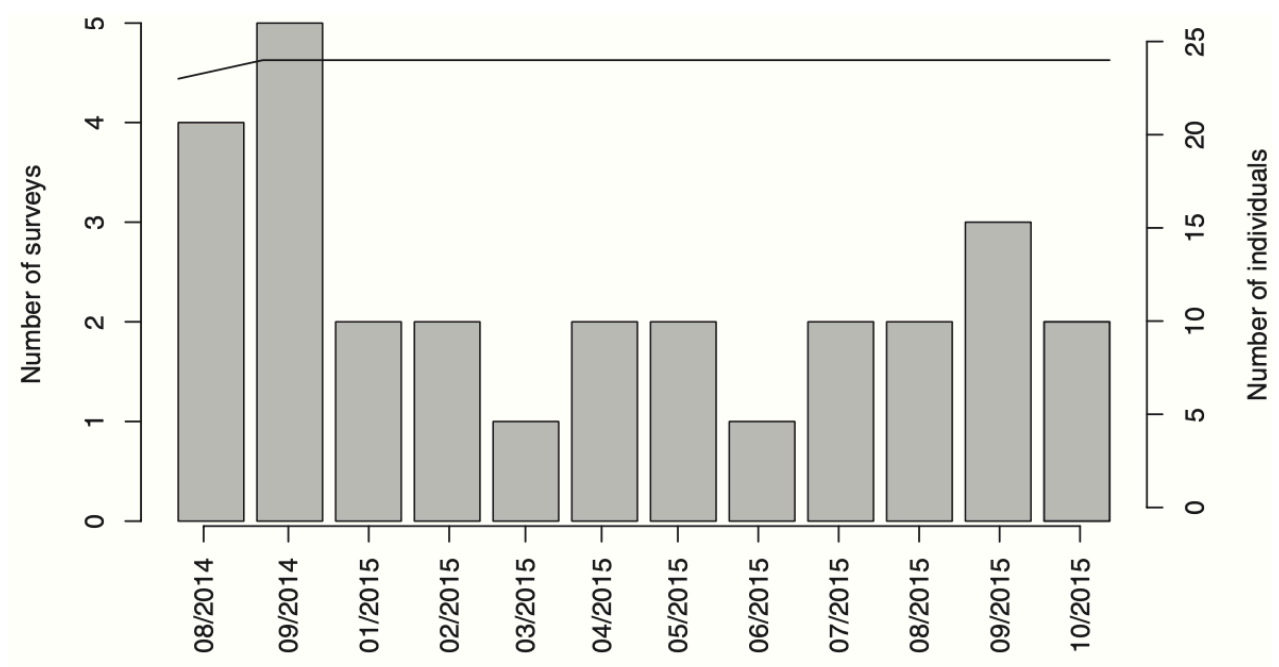

Figure 2. Distribution of the survey effort and cumulative number of identified individuals from August 2014 to October 2015. Calves have been excluded from the cumulative number of identified individuals.

a

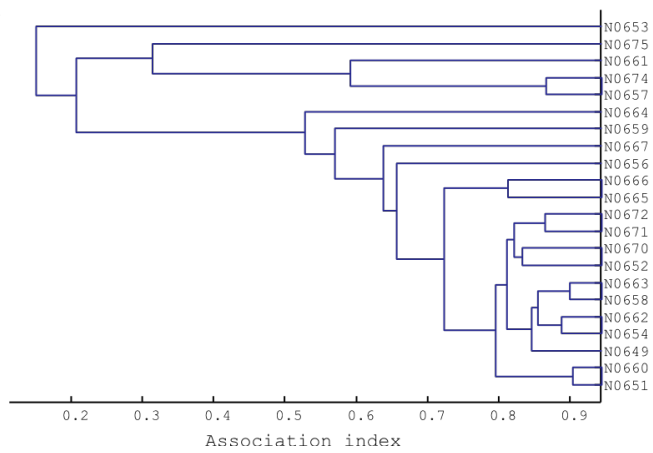

b

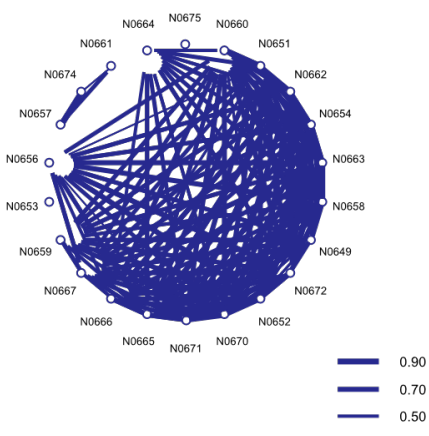

Figure 3. (a) Hierarchical cluster diagram of the half-weight index coefficients between photoidentified bottlenose dolphins encountered on more than $10 \mathrm{~d}(\mathrm{n}=22)$. Cluster cophenetic correlation coefficient was 0.96 . (b) Sociogram of the 22 bottlenose dolphins, association indices of $<0.5$ are not shown. Calves have been excluded in these figures.

\section{Acknowledgments}

We thank all fieldworkers who collected data in the field. We thank Rene Swift for English revision of the manuscript. We thank Francois Gally (Groupe d'Etudes des Cetaces du Cotentin) for photoidentification catalog comparison. This study was supported by the Agence des Aires Marines Protegees. The Observatoire PELAGIS is supported by the French Ministry in charge of Environment. ML was supported by Agence des Aires Marine Protegees and a Fyssen post-doctoral fellowship. 


\section{References}

Alexander, R. D. 1974. The evolution of social behavior. Annual Review of Ecology and Systematics 5:325-383.

Augusto, J. F., P. Rachinas-Lopes and M. E. Dos Santos. 2011. Social structure of the declining resident community of common bottlenose dolphins in the Sado Estuary, Portugal. Journal of the Marine Biological Association of the United Kingdom 92:1773-1782.

Beck, S., S. Kuningas, R. Esteban and A. D. Foote. 2012. The influence of ecology on sociality in the killer whale (Orcinus orca). Behavioral Ecology 23:246-253.

Bejder, L., D. Fletcher and S. Brager. 1998. A method for testing association patterns of social animals. Animal Behaviour 56:719-725.

Bouveroux, T., and J. Mallefet. 2010. Social structure of bottlenose dolphins, Tursiops truncatus, in Panama City, Florida. Journal of the Marine Biological Association of the United Kingdom 90:1685-1692.

Cairns, S. J., and S. J. Schwager. 1987. A comparison of association indexes. Animal Behaviour 35:1454-1469.

Calenge, C. 2006. The package "adehabitat" for the R software: A tool for the analysis of space and habitat use by animals. Ecological Modelling 197:516-519.

Connor, R. C., R. Wells, J. Mann and A. Read. 2000. The bottlenose dolphin: Social relationships in a fission-fusion society. Pages 91-126 in J. Mann, R. C. Connor, P. Tyack and H. Whitehead, eds. Cetacean societies: Field studies of whales and dolphins. University of Chicago Press, Chicago, IL.

Connor, R. C., J. J. Watson-Capps, W. B. Sherwin and M. Kr€utzen. 2011. A new level of complexity in the male alliance networks of Indian Ocean bottlenose dolphins (Tursiops sp.). Biology Letters 7:623-626.

Daura-Jorge, F. G., M. Cantor, S. N. Ingram, D. Lusseau and P. C. Simoes-Lopes. 2012. The structure of a bottlenose dolphin society is coupled to a unique foraging cooperation with artisanal fishermen. Biology Letters 8:702-705.

Foster, E. A., D. W. Franks, L. J. Morrell, K. C. Balcomb, K. M. Parsons, A. Van Ginneken and D. P. Croft. 2012. Social network correlates of food availability in an endangered population of killer whales, Orcinus orca. Animal Behaviour 83:731-736.

Frere, C. H., M. Kr€utzen, J. Mann, R. C. Connor, L. Bejder and W. B. Sherwin. 2010a. Social and genetic interactions drive fitness variation in a free-living dolphin population. Proceedings of the National Academy of Sciences of the United States of America 107:19949-19954.

Frere, C. H., M. Kr€utzen, J. Mann, et al. 2010b. Home range overlap, matrilineal and biparental kinship drive female associations in bottlenose dolphins. Animal Behaviour 80:481-486.

Hamilton, W. D. 1964. The genetical evolution of social behaviour. Journal of Theoretical Biology 7:1-52.

Hammond, P. S., S. A. Mizroch and G. P. Donovan. 1990. Individual recognition of cetaceans: Use of photo-identification and other techniques to estimate population parameters. Report of the International Whaling Commission (Special Issue 12). 440 pp.

Heithaus, M. R. 2001. Shark attacks on bottlenose dolphins (Tursiops aduncus) in Shark Bay, Western Australia: Attack rate, bite scar frequencies and attack seasonality. Marine Mammal Science 17:526-539.

Henzi, S. P., D. Lusseau, T. Weingrill, C. P. Van Schaik and L. Barrett. 2009. Cyclicity in the structure of female baboon social networks. Behavioral Ecology and Sociobiology 63:1015-1021.

ICES. 2014. Report of the Working Group on Marine Mammal Ecology (WGMME), 10-13 March 2014, Woods Hole, MA. ICES CM 2014/ACOM:27. 232 pp.

Kappeler, P. M., L. Barrett, D. T. Blumstein and T. H. Clutton-Brock. 2013. Constraints and flexibility in mammalian social behaviour: Introduction and synthesis. Philosophical Transactions of the Royal Society B-Biological Sciences 368:20120337.

Karczmarski, L., B. Wursig, G. Gailey, K. W. Larson and C. Vanderlip. 2005. Spinner dolphins in a remote Hawaiian atoll: Social grouping and population structure. Behavioral Ecology 16:675685. 
Krause, J., and G. D. Ruxton. 2002. Living in groups. Oxford University Press, Oxford, U.K.

Kreutzen, M., W. B. Sherwin, R. C. Connor, L. M. Barre, T. Van De Casteele, J. Mann and R. Brooks. 2003. Contrasting relatedness patterns in bottlenose dolphins (Tursiops sp.) with different alliance strategies. Proceedings of the Royal Society B-Biological Sciences 270:497-502.

Lehmann, J., and C. Boesch. 2004. To fission or to fusion: Effects of community size on wild chimpanzee (Pan troglodytes verus) social organization. Behavioral Ecology and Sociobiology 56:207-216.

Liret, C. 2001. Domaine vital, utilisation de l'espace et des ressources: Les grands dauphins, Tursiops truncatus de l'^ıle de Sein [Home range, habitat and resource use: Bottlenose dolphins, Tursiops truncatus of $I^{\prime} \wedge$ ıle de Sein]. Ph.D. dissertation, University of Bretagne Occidentale, Brest, France. 155 pp.

Liret, C., M. E. Baines, P. G. H. Evans, F. Gourmelon, I. Le Berre, P. Hammond and B. Wilson. 2006. TURSIOPS: Reseau europeen d'etude des grands dauphins [TURSIOPS: European network of bottlenose dolphin studies]. INTERREG IIC Programme project report. $63 \mathrm{pp}$.

Louis, M., and V. Ridoux. 2015. Suivi des grands dauphins et des petits cetaces dans le Parc naturel marin d'Iroise: Analyse des donnees [Monitoring of bottlenose dolphins and small cetaceans in the Parc natural marin d'Iroise: Data analyses]. Convention $n^{\circ}$ 920/ UMS 3462/PNMI. Observatoire Pelagis, La Rochelle, France. 30 pp.

Louis, M., F. Gally, C. Barbraud, et al. 2015. Social structure and abundance of coastal bottlenose dolphins, Tursiops truncatus, in the Normano-Breton Gulf, English Channel. Journal of Mammalogy 96:481-493.

Lusseau, D., K. Schneider, O. J. Boisseau, P. Haase, E. Slooten and S. M. Dawson. 2003. The bottlenose dolphin community of Doubtful Sound features a large proportion of longlasting associations: Can geographic isolation explain this unique trait? Behavioral Ecology and Sociobiology 54:396-405.

Newman, M. E. J. 2004. Analysis of weighted networks. Physical. Review E70:056131.

R Core Team. 2015. R: A language and environment for statistical computing. R Foundation for Statistical Computing, Vienna, Austria.

Rubenstein, D. I., and R. W. Wrangham. 1986. Ecological aspects of social evolution: Birds and mammals. Princeton University Press, Princeton, NJ.

Silk, J. B., S. C. Alberts and J. Altmann. 2003. Social bonds of female baboons enhance infant survival. Science 302:1231-1234.

Silk, J. B., J. C. Beehner, T. J. Bergman, et al. 2009. The benefits of social capital: Close social bonds among female baboons enhance offspring survival. Proceedings of the Royal Society BBiological Sciences 276:3099-3104.

van Schaik, C. P. 1989. The ecology of social relationships amongst female primates. Pages 195-218 in V. Standen and R. A. Foley, eds. Comparative socioecology. Blackwell, Oxford, U.K.

Wells, R. S., M. D. Scott and A. B. Irvine. 1987. The social structure of free-ranging bottlenose dolphins. Pages 247-305 in H. Genoways, ed. Current mammalogy. Plenum Press, New York, NY.

Whitehead, H. 1999. Testing association patterns of social animals. Animal Behaviour 57:26- 229.

Whitehead, H. 2008. Analyzing animal societies: Quantitative methods for vertebrate social analysis. University of Chicago Press, Chicago, IL.

Whitehead, H. 2009. SOCPROG programs: Analysing animal social structures. Behavioral Ecology and Sociobiology 63:765-778.

Wiszniewski, J., S. J. Allen and L. M. M€oller. 2009. Social cohesion in a hierarchically structured embayment population of Indo-Pacific bottlenose dolphins. Animal Behaviour 77:1449-1457.

Wiszniewski, J., D. Lusseau and L. M. M€oller. 2010. Female bisexual kinship ties maintain social cohesion in a dolphin network. Animal Behaviour 80:895-904.

Wiszniewski, J., S. Corrigan, L. B. Beheregaray and L. M. M€oller. 2012. Male reproductive success increases with alliance size in Indo-Pacific bottlenose dolphins. Journal of Animal Ecology 81:423-431. 
Wittemyer, G., I. Douglas-Hamilton and W. M. Getz. 2005. The socioecology of elephants: Analysis of the processes creating multitiered social structures. Animal Behaviour 69:1357-1371.

Worton, B. J. 1989. Kernel methods for estimating the utilization distribution in home-range studies. Ecology 70:164-168. 